\title{
Alteration of Plasma Brain Natriuretic Peptide Level After Acute Moderate Exercise in Professional Athletes
}

\author{
Homa Sheikhani ${ }^{1^{*}}$, Mohammad Ali Babaee Beygi ${ }^{2}$, Farhad Daryanoosh ${ }^{3}$, Bijan Jafari ${ }^{3}$ \\ ${ }^{1}$ Physical Education Department, Tarbiat Moalem University, Tehran, IR Iran \\ ${ }^{2}$ Cardiovascular Research Center, Shiraz University of Medical Sciences, Shiraz, IR Iran \\ ${ }^{3}$ Physical Education Department, School of Education and Psychology, Shiraz University, Shiraz, IR Iran
}

\section{A R T I C L E I N F O \\ Article type: \\ Original Article \\ Article history: \\ Received:10 Apr 2011 \\ Revised: 17 Apr 2011 \\ Accepted: 26 Apr 2011}

\section{Keywords:}

Brain

Natriuretic Peptide

Exercise

\begin{abstract}
A B S T R A C T
Background: Cardiac fatigue or myocardial damage following exercise until complete exhaustion can increase blood levels of brain natriuretic peptide (BNP) in athletes. Objectives: The aim of the present study was to investigate the effect of resistance and acute moderate aerobic exercise on alterations in BNP levels in professional athletes. Materials and Methods: Forty professional athletes who had at least 3 years of a championship background in track and field (aerobic group) or body building (resistance group) volunteered to participate in the present study. Track and field athletes $(n=20)$ were requested to run $8 \mathrm{~km}$ at $60 \%$ to $70 \%$ of maximum heart rate. Body building athletes $(n=20)$ performed a resistance training session of 5 exercises in 3 sets of 10 repetitions at $75 \%$ of $1 \mathrm{RM}$ (bench press, seated row, leg extension, leg curl, and leg press). Before and immediately after the exercise, plasma BNP levels of both groups of athletes were measured by PATHFASTTM NT-proBNP assay, an immunochemiluminescent assay using two polyclonal antibodies in sandwich test format, on a PATHFASTTM automated analyzer. Results: Plasma BNP levels immediately following exercise increased significantly as compared with baseline values. Plasma BNP concentrations in the aerobic group were significantly higher than in the resistance group before and after exercise. Moreover, the increase in mean BNP concentrations in aerobic athletes was 7 times more than in resistance athletes.

Conclusions: BNP levels in athlete who performed distance exercises increased significantly compared with resistance training. Possibly exercise program type, intensity of exercise, volume of exercise program, and field sport can be factors of changes in BNP levels.

Copyright @ 2011 Kowsar Corp. All rights reserved.
\end{abstract}

\section{- Implication for health policy/practice/research/medical education:}

As the athletes in different fields; especially during the competitions, are under heavy physical pressure, which is sometimes more than their tolerance, so it is essential for the professional athletes that their BNP levels be studied as an index for their heart function.

\section{- Please cite this paper as:}

Sheikhani H, Babaee Beygi MA, Daryanoosh F, Jafari B. Alteration of Plasma Brain Natriuretic Peptide Level After Acute Moderate Exercise in Professional Athletes. Int Cardiovasc Res J.2011;5(4):148-50. DOI:10.5812/icrj.4648

\section{Background}

Physiologists and cardiologists have investigated the effect of exercise on the cardioaortic system, and the results indicated that exercise and physical activity can be used as essential and appropriate ways to prevent heart

\footnotetext{
* Corresponding author: Homa Sheikhani, Cardiovascular Research Center, Shiraz University of Medical Sciences, Zand St, Shiraz, IR Iran. Tel: +989366744743,E-mail:hsheikhani@yahoo.com

DOI:10.5812/icrj.4648

Copyright @2011 Kowsar Corp. All rights reserved.
}

disease and prolong life expectancy (1). Lack of physical readiness and activity and mortality, induced by heart diseases, have been a concern of specialists, and they recommended physical activity to prevent heart diseases (1). BNP is used in medical science to evaluate the risk of heart disease, heart attack, or acute coronary syndrome (2). Peptide hormone type B (BNP) consists of 32 amino acids, and first set asided from pig's brain by sudoh et al. (1988) (3). This hormone is mainly synthesized and secreted by ventricular myoblasts in response to physical stress and exertion by heart muscle $(3,4)$. BNP can be 
an active or non-active hormone (NT-Pro-BNP, BNP). This hormone affects some body functions, such as vasoconstriction, urine volume, sodium excretion, sympathic system suppression, and the renin-argenin system (5). Exercise causes a long-term increase in BNP levels. Although these changes do not remain in plasma long, they can be recognized 1 hour after exercise (6). Some research has suggested that BNP is related to physical readiness, intensity, and volume of exercise performance (7). Recent research has stated that BNP levels in myocardium of exercise-induced ischemic patients increase slightly, but BNP increases have a significant and direct relationship with ischemic levels. Some researchers believe that increases in sympathetic activity during acute exercises lead to increases in BNP (8). Moreover, cardiac fatigue or myocardial damage following exercise until complete exhaustion can happen and increase BNP levels (9). The studies assessing the impact of acute exercise on BNP levels in healthy humans are insufficient and controversial. Elevated natriuretic peptide levels are detected in healthy endurance male athletes immediately after prolonged strenuous exercise and have been interpreted to be the result of exercise-induced subclinical myocardial cell damage (5). Conversely, in female marathon runners, elevated BNP levels were found only 1 day after a marathon (6). A recent study also showed that short-term maximal physical exercise in healthy individuals led to a fast and transient rise in plasma BNP (7).

\section{Objectives}

The aim of the present study was to study the effect of acute moderate exercise on BNP levels in professional athletes.

\section{Materials and Methods}

Forty professional athletes who had at least 3 years of a championship background in track and field ( $n=20$, aerobic group) or body building ( $\mathrm{n}=20$, resistance group) volunteered to participate in the present study. All athletes became familiar with the research procedure and gave their consent to participate in the study. Through interviews, athletes were evaluated with respect to general health, cardiac-respiratory fitness, drug disuse, and disease. Before exercise, blood samples were collected from all athletes. Track and field athletes were requested to run 8 kilometers at $60 \%$ to $70 \%$ of maximum heart rate. Body building athletes performed a resistance training session of 5 exercises in 3 sets of 10 repetitions at $75 \%$ of $1 \mathrm{RM}$. Their resistance exercises included bench press, seated row, leg extension, leg curl, and leg press. Approximately 2 minutes of rest was allowed between each ex- ercise. Immediately after exercise, blood samples were taken from athletes. Plasma BNP levels were measured by PATHFASTTM NT-proBNP assay, an immunochemiluminescent assay using two polyclonal antibodies in sandwich test format, on a PATHFASTTM automated analyzer.

Pre- and post-exercise concentrations of BNP were analyzed by paired T-test within groups. Plasma BNP concentrations and their pre- and post-exercise differences were compared by independent sample T-test between two different groups using SPSS version 16. Data presented as mean \pm standard deviation. $P$-value less than 0.05 considered significant.

\section{Results}

The physical characteristics of athletes are shown in Table 1. Results of the paired t-test showed that plasma BNP concentrations increased significantly after exercise in both aerobic and resistance groups $(P=0.001$; Figure $1 a)$. In addition, the independent T-test showed that plasma BNP Concentrations in the aerobic group were significantly greater than in the resistance group before and after exercise $(P=0.001$; Figure $1 a)$. Moreover, the increase in mean BNP concentrations in aerobic athletes was 7 times greater than in resistance athletes $(P=0.001$; Figure $1 b)$.

\section{Discussion}

BNP is protective against high pressure in athletes during vigorous exercise activity or in an appropriate state of physical readiness, causing extra pressure on the heart, causing hypertension. This can be prevented through vasodilatation or by increasing the urine volume to decrease plasma. In increasing perspiration or decreasing plasma during exercise and hypertension, the body needs decrease plasma levels in order to aid BNP secretion to meet this goal (10). Cardiac hormones have diuretic effects on sodium excretion from urine, and vasodilatation delays heart failure. BNP secretion is a sign of overpressure in the heart. Specialists consider BNP level or peptide natriuretic type B a simple, objective measure for heart function. These measurements are used to recognize heart failure (11). People with heart failure have considerably higher plasma changes following exercise compared with healthy subjects. Our results showed that mean BNP increased following exercise compared with before activity. Aerobic exercise activity caused an $84.4 \%$ increase in athletes, while resistance exercise led to a 30.6\% increase in athletes, possibly because BNP levels can contribute to physical movement levels regarding exercise activity. One of the main reasons of increased BNP circulation levels is systolic or diastolic dysfunction of the heart $(6,10-13)$. The dysfunction occurs following

\begin{tabular}{lllll}
\hline \multicolumn{1}{l}{ Table 1. Physical Characteristics of Professional Athletes $(\mathrm{n}=40)$} & Which Volunteered in Aerobic and Resistance Acute Moderate Exercise & \\
\hline Group & Height $(\mathbf{c m})$ & Weight $(\mathbf{k g})$ & Age $(\mathbf{y})$ & Body Mass Index \\
\hline Aerobic exercise & $177 \pm 1.2$ & $83 \pm 2.2$ & $27 \pm 0.5$ & $26.5 \pm 0.5$ \\
Resistance exercise & $175 \pm 3.1$ & $82 \pm 6.1$ & $27.2 \pm 0.5$ & $26.7 \pm 0.5$ \\
\hline
\end{tabular}


Figure 1. Comparison means (and standard deviation) of a; plasma concentration changes in aerobic group (from $a=26.3$ to $b=48.5$ ) and in resistance group (from $\mathrm{c}=12.02$ to $\mathrm{d}=15.7$ ) and $\mathrm{b}$; differences of brain natriuretic peptide (BNP, ng/L) before and after aerobic $(\mathrm{a}=22.2 \pm 10.94)$ and resistance $(b=3.7 \pm 3.2)$ acute moderate exercise in professional athletes $(n=40)$.
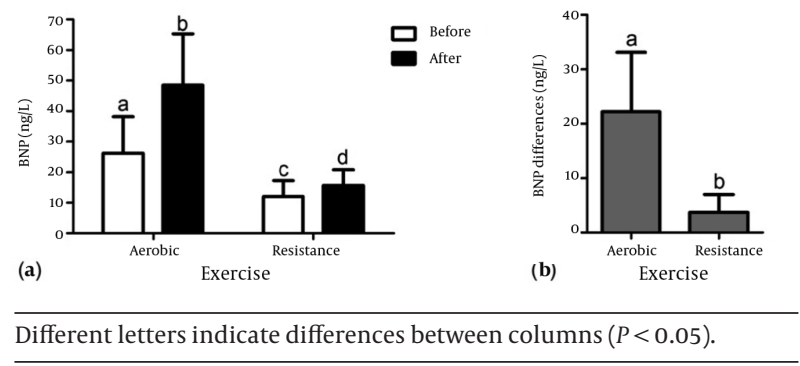

overstretching of the left ventricular wall, induced by overtension of the heart during intense exercise, activating beyond an athlete's capacity when controlling blood pressure; as a result, the ventricle must produce more BNP, leading to increased plasma levels (14). Recently, athletes in more energetic exercises must tolerate more stress than before, which is one of the most important side effects of this physical stress of pressure on myocardium. This can result in systolic and diastolic dysfunction and, eventually, heart failure (15).

As perceived from the results of our study, the plasma level of this hormone is more affected in more energetic exercises than resistance training. Furthermore, the results of a recent survey indicated that BNP levels in athletes performing distance exercises increased significantly as compared with resistance training. Possibly, exercise program type, intensity of exercise, volume of exercise program, and field sport can be factors of BNP level. In summary, long-term acute exercise increases BNP independently. Therefore, differences in its release must be considered, even when the clinical values are more than BNP levels during and after exercise, which can damage the myocardium, leading to protective effects. The circulating BNP level increases significant in healthy persons immediately after exercise. Thus, we suggest measuring plasma BNP; blood should not been taken promptly after exercise so that they are not affected by potential physical variables.

\section{Acknowledgments}

This work was financially supported by Vice chancellor for research of Shiraz University of Medical Science. The author declares that they have no conflicts of interest.

\section{Financial Disclosure}

None declared.

\section{Funding/Support}

None declared.

\section{References}

1. Holmes SJ, Espiner EA, Richards AM, Yandle TG, Frampton C. Renal, endocrine, and hemodynamic effects of human brain natriuretic peptide in normal man. I Clin Endocrinol Metab. 1993;76(1):91-6.

2. Deuster PA, Chrousos GP, Luger A, DeBolt JE, Bernier LL, Trostmann UH, et al. Hormonal and metabolic responses of untrained, moderately trained, and highly trained men to three exercise intensities. Metabolism.1989;38(2):141-8.

3. McDonagh TA, Robb SD, Murdoch DR, Morton JJ, Ford I, Morrison $\mathrm{CE}$, et al. Biochemical detection of left-ventricular systolic dysfunction. Lancet. 1998;351(9095):9-13.

4. Donald RA, Perry EG, Wittert GA, Chapman M, Livesey JH, Ellis MJ, et al. The plasma ACTH, AVP, CRH and catecholamine responses to conventional and laparoscopic cholecystectomy. Clin Endocrinol (Oxf). 1993;38(6):609-15.

5. Detaint D, Messika-Zeitoun D, Chen HH, Rossi A, Avierinos JF Scott C, et al. Association of B-type natriuretic peptide activation to left ventricular end-systolic remodeling in organic and functional mitral regurgitation. Am J Cardiol. 2006;97(7):1029-34.

6. Kato M, Kinugawa T, Ogino K, Endo A, Osaki S, Igawa O, et al. Augmented response in plasma brain natriuretic peptide to dynamic exercise in patients with left ventricular dysfunction and congestive heart failure.J Intern Med. 2000;248(4):309-15.

7. de Groote P, Dagorn J, Soudan B, Lamblin N, McFadden E, Bauters C. B-type natriuretic peptide and peak exercise oxygen consumption provide independent information for risk stratification in patients with stable congestive heart failure. J Am Coll Cardiol. 2004;43(9):1584-9.

8. Sabatine MS, Morrow DA, de Lemos JA, Omland T, Desai MY, Tanasijevic $\mathrm{M}$, et al. Acute changes in circulating natriuretic peptide levels in relation to myocardial ischemia. J Am Coll Cardiol. 2004;44(10):1988-95.

9. Madaric J, Vanderheyden M, Van Laethem C, Verhamme K, Feys A, Goethals M, et al. Early and late effects of cardiac resynchronization therapy on exercise-induced mitral regurgitation: relationship with left ventricular dyssynchrony, remodelling and cardiopulmonary performance. Eur Heart J. 2007;28(17):2134-41.

10. Yandle TG, Richards AM, Gilbert A, Fisher S, Holmes S, Espiner EA. Assay of brain natriuretic peptide (BNP) in human plasma: evidence for high molecular weight BNP as a major plasma component in heart failure. J Clin Endocrinol Metab. 1993;76(4):832-8.

11. O'Donoghue M, Chen A, Baggish AL, Anwaruddin S, Krauser DG, Tung R, et al. The effects of ejection fraction on N-terminal ProBNP and BNP levels in patients with acute CHF: analysis from the ProBNP Investigation of Dyspnea in the Emergency Department (PRIDE) study. J Card Fail. 2005;11(5 Suppl):S9-14.

12. Nussberger J, Fasanella d'Amore T, Porchet M, Waeber B, Brunner DB, Brunner HR, et al. Repeated administration of the converting enzyme inhibitor cilazapril to normal volunteers. J Cardiovasc Pharmacol.1987;9(1):39-44.

13. Lewis JG, Manley L, Whitlow JC, Elder PA. Production of a monoclonal antibody to cortisol: application to a direct enzymelinked immunosorbent assay of plasma. Steroids.1992;57(2):82-5.

14. Smoak B, Deuster P, Rabin D, Chrousos G. Corticotropin-releasing hormone is not the sole factor mediating exercise-induced adrenocorticotropin release in humans. J Clin Endocrinol Metab. 1991;73(2):302-6.

15. Spurway NC. Aerobic exercise, anaerobic exercise and the lactate threshold. BrMed Bull.1992;48(3):569-91. 